\title{
LANCASHIRE SECTION: Meeting at Institute, Manchester, 9th July, 1920. Sir Herbert A. Dixon, Bart., in the Chair. THE PRODUCTION OF COTTON IN EGYPT
}

\section{Nicolas Parachimonas}

To cite this article: Nicolas Parachimonas (1920) LANCASHIRE SECTION: Meeting at Institute, Manchester, 9th July, 1920. Sir Herbert A. Dixon, Bart., in the Chair. THE PRODUCTION OF COTTON IN EGYPT, Journal of the Textile Institute Proceedings and Abstracts, 11:9, 243-247, DOI: $10.1080 / 00405002008631134$

To link to this article: http://dx.doi.org/10.1080/00405002008631134

曲 Published online: 25 Nov 2008.

Submit your article to this journal $₫$

山 Article views: 3

Q View related articles ¿

7 Citing articles: 1 View citing articles 


\section{PROCEEDINGS OF THE INSTITUTE}

\section{LANCASHIRE SECTION}

Mecting at Institute, Manchester, 9th July, 1920.

Sir Herbert A. Dixon, Bart., in the Chair.

THE PRODUCTION OF COTTON IN EGYPT

By Nicolas Parachimonas.

ThE spectre of a shortage of cotton is hanging over us, as it were, in a threatening manner. We can all apprehend the troublesome consequences which the disappearance in the near future of the equilibrium between the production of cotton and the consumption of cotton will force upon us. People are relying on an increase in the production in America, and are also looking forward to the possibility of crenting new centres of production in Africa. But I fear that their hopes are misplaced, and that we must take it for granted that the regions where the soil or the elimate, or both, can take on the production and cultivation of cotton are not numerous; and those that are suitable to produce it are not only not organised as regards means of communication, irrigation and financial equipment, but-and this is most important-they cannot get tho lahour, either rom it point of view of numbers or skill, and there are no appropriate varieties which can be planted there. As you are aware, a great deal of abour is required for the cultivation of cottonmuch capital, irrigation works, and suitable means of transport. It follows therefore that to create new centres of production you have to bring together and unite all your resources, with one common object.

We must admit that for the present nothing really practical is being attempted. We are still living on hopes and theoretical experiments. Nevertheless, the situation is serious from many points of view, as you well know, and it is not difficult to foresee that a policy of procrastination can only bring about irre. trievable consequences. Whichever way you look at it, it seems to me that the production of Egyptian cotton, for which the demand is greatly on the increase owing to new industrial uses that it is being put to-take for instance the demand for the tyre industry-is of the very greatest importance. Therefore everything that appertains to its development cannot but be of the greatest interest to you, seeing that in a very great measure it is Egyptian cotton which constitutes the power of the cotton industry.

It is this consideration then which makes it clear that it is of interest that I should speak to you and oxplain to you what has been done in Egypt up to this day as regards the production of cotton, and to examine together with you what might still be done to increase the production.

It has taken, as you know, fully 100 years for that country to arrive at producing what it actually does. One might have thought that because Egypt is organised for the production of cotton, this production might have been increased ad infinitum. Unfortunately, the acreage is limited. Surrounded as it is by the Libyan and Arabian deserts, and to the north by the Mediterranean, there are only six to seven million acres in the Valley of the Nile which can be put under cultivation. Of these, there are actually four-fifths under cultivation, and of these, again, owing to the rotation of different kinds of crops, there are only about two million acres under cotton cultivation each year. As you will see, then, there still remain vast tracts of land which could be made capable of cultivation and which could also produce cotton. But bear in mind that it would be impossible to increase as much as we would like the production of cotton seeing that the territory is limited.

Now let us see whether some other way of increasing the production could not be found. I think that such a thing is possible, and such a possibility must be looked for in the conditions under which cotton is eultivated in Egypt. The prosperity of the production of cotton in Egypt is subordinated by the question of irrigation, by the conditions of the drainage, by the quality of the soil, the diseases, and by the varieties that are cultivated. It follows, therefore, that every improvement in the case of any of the above factors would obviously have the effect of increasing the production.

There is much to be done as regards irrigation and drainage. Notwithstanding the great work done during the last few decades, the irrigation is not as it should be. There are large tracts which are not properly served, and if we go into details we find considerable defects. In reality, large tracts are badly drained and the system of canals for irrigation purposes is not sufficient for agricultural needs. In the majority of cases, the water is not distributed effectively, especially cluring the months of June and July-to the detriment of the crop. Looking into these details, we find that many lands suffer from insufficient water through the drains not working properly, and it is sad that cultivators should have to complain and that no notice is taken of their complaints. I will not say that the Ministry of Public Works has not achieved a great deal for the agriculture of the country ; and if I point out to you these disadvantages or shortcomings it is only with the object of proving to you the importance that an end should be put to a prejudicial state of things.

Keep in mind that such a state of things contributes greatly to a smaller out-turn in the cotton crop, and this diminution can be estimated at 15 per cent.

Do not imagine that what has to be done is difficult. There are some very good men in the Ministry of Public Works in Egypt, and, besides, the financial position of Egypt is such as to make it well able to do all this work; and in spite of all that is said, I maintain that there is enough water not only to remedy.this insufficiency but also to bring under cultivation all the tracts of land which remain uncultivated. 
As regards the soil, all the lands in Egypt with very few exceptions are suitable to the production of cotton; from south of Assouan to the Mediterranean coast, and from the Arabian to the Libyan deserts. The productiveness ought naturally to be proportionate to the richness of the soil. Unfortunately, this is not the case with the "Sakellarides" variety. Very great diseases attack the plants and seem to thrive wherever the plants are luxuriant.

In Egypt, we find two kinds of diseases in the cotton plants. Firstly, we have the diseases due to microbes, and secondly the diseases due to insects. As regards the first, which do a great deal of damage, we have not found any remedy. But my studies have proved to me that we can fight these diseases by putting up against them varieties which can resist them. As regards the second, which are even more destructive, we have been able to fight efficaciously against the Worm of the leaf (Proedenia Litoratis) by gathoring the eggs which the butterfly lays on the leaves. And as regards the Boll-Worm (Earcas) we have not been able to do anything against it. The insect which is the most dreaded is the Pink Boll-Worm or Ver Rose (Gelechia), for the reason that it multiplies in the most prolific way and at a time when the greater part of the capsules are not yet ripe; it is therefore most destructive. This is the disease which often destroys whole districts and sometimes even three-guarters of the crop. Unfortunately, there does not appear to be any efficacious remedy, and I do not see any hope of the probability of either destroying it or lessening its ravages in spite of precautionary measures of disinfection, which have been tried by the Ministry of Agriculture. 'The reason for this is that the habits of this insect are so perfidious. Let us hope that in time its virulence will weaken.

The failure of all these attempted remedies which havo been tried against all these disenses, not only in Egypt but in many other parts of the world, proves how difficult it is to fight them in a direct manner : and it is this circumstance which urget on me the need to try and find if it were not possible to arrive at a satisfactory solution of the problem through indirect means.

As we have seen then, gentlemen, there are many difficulties which intervene towards influencing the production of cotton in Egypt. But there are further clificulties, quite as important, if not more so, which are to be met with and which render the production even more unstable. To give you a more complete explanation I would have to touch on many points both from a botanist's and agriculturist's point of view, and all this would be much too technical. So I will limit myself to telling you something about the nature of the plant which has a direct bearing not only on the production but on the cotton industry also, which is so interested in the quality of what is produced.

The cotton plant, in order to satisfy the industry of agriculture, and at the same time the textile industry, must fulfil two essential conditions. It must produce a sufficient quantity to balance the nett cost of production plus a certain amount of profit: it must also produce a quality which would be suitable to the uses for which the textile industry requires it. The ideal thing, of course, would be to have plants which would produce in an invariable manner a good out-turn, and at the same time not only one single quality of fibre, but as many qualities as the industry would like to have for each and every particular or special use. Verily, it would have been of great importance to have been able to create plants which would yield a maximum of productiveness among all the difficulties of cultivation, climate, nature of the soil, and the numerous diseases; and these same plants to produce as many qualities as the cotton industry could make use of. It would be especially profitable, too, to be able always to have the same qualities so as to preserve that standard of quality which the industry had got accustomed to, and thus do away with the inevitable troubles which every change of quelity brings along with it. Unfortunately, such an ideal as this is not to be met with in Egypt.

The Egyptian cotton plant is what one might call a very capricious plant. By nature it is fickle; that is to say, it is most sensitive to the modifications, however slight, of the quality of the soil, to the climatic conditions, and, an even more serious thing, the Egyptian varieties are unable at the end of a few years to resist the diseases which appear ; in this way for plysiological reasons they become less and less productive. It is for these reasons then that you caunot always cultivate in Egypt the same varieties; on the contrary, one is obliged to have recourse to younger and more vigorous varieties. And taking it for granted that one cannot obtain varieties which are capable of producing the same type of fibre as existed before, it follows that the producer in Egypt is obliged, periodically, to put before the consumer new varieties. It is therefore of the greatest interest that the cotton industry should synchronise and adapt itself to what the Egyptian producer finds it possible to do. I have been presching this for 25 years, but without success. And it is for this very reason that I ask all of you who understand these things to allow me to-day to call your earnest attention to this point. It is a question of a necessity which has been definitely proved and does not even admit of any discussion, and unless the cotton industry takes it seriously to heart it will never be able to get on with Egyptian agriculture.

T'ake the variety " Saliellarides," which has rendered such great services both to agriculture and to the cotton inclustry. This variety is actually on the wane. It has become most sensitive to the attacks of the pink boll-worm and other diseases, and has accordingly lost a great deal of its productiveness. The majority of spinners find it suitable for their requirements, but the producer has ceased to get adequate remunera. tion for his trouble in cultivating it.

You will surely agree with me that it is quite un. realisable that we can go on asking the producer to continue cultivating something unprofitable. What better example then than this can I give you that it is very important that spinners should follow closely that which is inevitable in Egypt. 
I should not like you to think I am saying anything unjust of anyone if I tell you that a great many spinners will not trouble to give a trial to some of the new qualities which appear on the market, and that they only use them when they cannot get any other. All the same, the producer has invariably forced upon the industry those varieties which have given him a steady out-turn, and a proof of this is to be found in the history of the evolution of the cotton plant in Egypt for the last hundred years.

Now let us have a retrospective look at this evolution. It is just one hundred years ago that the Khedive, Mohamed Ali Pacha, introduced into Egypt cotton seed from India. This species was eultivated in the Nile Valley. It became acclimatised, and adapting itself to the special conditions of this region it created the standard of Egyptian cotton. Later on, Jumel favoured another type of cotton which an officer, named "Macan," brought from the Soudan, for the reason that its quality was much superior. (It was superior in quality to the "Salsellarides" of to-day.)

Notwithstanding the efforts of the Egyptian Govern. ment in furthering the production of this species, its cultivation never became general as it was not found suitable in all the different provinces. And after much experimenting which was very deceptive, its cultivation was restricted to certain districts, and especially to the district of Calline, in the Gharbieh province, where it degenerated completely and took on the name of "Galini" or "Galineti," a variety which perhaps some of you remember. It has disappeared, leaving as its descendant az variety which played a very important part later on: I refer to the variety known as "Joanovich."

As "Joanovich" could only be suitably grown in the same district as the variety "Macau," and es it also deteriorated, it was given up just as spinners were beginning to appreciate its qualities. As for the Indian variety, it did not prosper. Its quality became coarser and coarser; it became dislocated into many unstable sub-varieties ; it lost its importance, and its cultivation was restricted to the district of Menoufieh, of which the most important (the district of Ashmoun) gave it its name, "Ashmouni." Here it thrived for some time and then disappeared from Lower Egypt. Its cultivation was continued in Upper Egypt, where it thrived better than all the other known varieties. It has deteriorated and has almost ceased to exist, and it has been replaced almost everywhere by the variety known as "Zagora," which variety I was lucky enough to create myself. Its condition had become so bad that as soon as the variety "Zagora" appeared the cultivators at once trok it up, and in two years' time its cultivation became general.

The haphazard cross-breeding between the Indian species and the "Macau" appear to have been the origin of all the varieties of cotton which have been cultivated in Egypt up to this day.

In chronological order, with the exception of certain varieties of sthall importance and which have played no important part, we have had the variety " Mit Afifi," and you all know the services it has rendered your industry. It is this variety which has enriched
Egypt and which has given such a great development to your industrial centres.

This variety very nearly died away before develop. ing, when Mr. Canavas, a Greek, living at Benha, who perceived its good qualities, started multiplying it, and when he sent the cotton to Liverpool no spinner would give it a trial on account of its brown colour, which they ascribed to deterioration brought about by dampness. Notwithstanding this, you all know how quickly, later on, it was most successful both in Egypt and for your industry.

The good points of this variety have been so impressed on my memory that I remember the late Lord Kitchener's recommendation to me-he may have been inspired by spinners - asking me in 1913 to try and create a variety similar to that "Mit Afifi " and which at the time had reached the lowest degree of its deterioration. I may tell you thet following his advice I created a variety which I have named "Kitchener," but which I am not propagating as I am convinced that spinners want something better than the type "Mit Afifi."

As soon as the deterioration of the "Mit Afifi" had begun, the need for a new variety began to make itself felt. The Greeks established in Egypt began, on all sides, to select verious varieties to replace the "Mit Afifi." The rivalry ereated bore fruit, and at length Mr. Sakellarides selected the variety which is called after him, and you know better than I do the services it has rendered. The cultivation of this variety began to spread in 1911. This one, too, was badly received by the majority of spinners, who preferred the "Nubari," which I had created. But the demand for the uses of war and from the tyre industry brought about later on a great development ; so much so that the cultivation of this variety became general over Lower Egypt, to the detriment of the cultivation of the other qualities.

But, as I have already told you, the agricultural advantages of this beautiful variety did not last very long, and already since 1915 more often than not it is a source of disappointment to the cultivator. Owing to its deterioretion it has become the cause of an important falling off in its production. You will see then that the part that the cotton plant plays compared to the amount it yields is of the very greatest importance. I would ask you to bear well in your minds the revelations which disentangle themselves from the history of the evolution of the cotton plant in Egypt. We learn that we are under the domination of two facts, of two necessery things, the one being the sequel to the other.

On the one hand, we see that all the varieties lose their productiveness at the end of a certain time and thus only last a few years, so that as soon as they are on the wane they degenerate, become dislocated

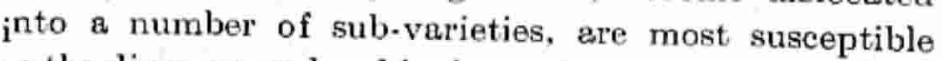
$t^{\circ}$ the diseases, and end by becoming unremunerative.

On the other hand, to counterect this state of affairs, the Egyptian producer finds himself absolutely obliged to abandon the degenerate varieties and to look out for others, younger, more robust, and more productive. 
At one time an opinion gained ground in Egypt which had the effect of malcing people bolieve that there was a likelihood that the decay in the varieties could be checked by selecting the seed and only cultivating the best of it. And for some time the Ministry of Agriculture took drastic steps to see this was done. Unfortunately, all these measures were of no avail.

If one wishes to continue cultivating cotton in Egypt, one must always look for new plants, which before everything must prove remunerative to the cultivator.

One must be able to replace at the opportune moment the existing varieties before the degeneration begins to bring about trouble both in the production and quality. One must also know beforehand the age of these varieties so as to make certain of as long a period of stability as possible. Taking it for granted that, periodically the cotton plant is attacked by diseases. one must be able to have varieties which possess the desired resistance to the mischief. And, at last, when one possesses a large number of varieties, not only will one have, the facility of picking out those which will be able to carry out the conditions above-mentioned, but these would also allow us to choose the qualities of cotton which the cotton industry would like to have. It is evidently only by solving these problems that we will arrive at making safe for Egypt a more stable production of cotton, an eventually larger production, and the preserving of the standard of Egyptian cotton.

The great necessity of solving these problems was my chief thought during my studies of the question.

As a basis of my research, I employed the process of artificial "pollenisation," which allowed me to do that which nature does blindly: that is to say, by making cross-breeding between a tremendous number of plants, and wherein man's intelligence prevails over luck or chance.

By my process, which consists in reperting the cross. breeding for many years in succession and by choosing properly the parent plents, I was able to notice the following remarkable phenomenon:-Among the numerous cross-breedings which I obtained, there sprang up certain plants quite typical which do not resemble at all the parents which contributed to their creation. These plants possess the characteristics of the "mutunts," described as being of sudden appearance by De Vries and his pupils. After 26 years of hard work I am happy to inform you that I have obtained results which appear to me most favourable. I have in reserve a very large number of varieties which appear to me sufficient not only for present needs but also for many decades hence. And this, gentlemen, is what $I$ have been able to accomplish through my own initiative.

Now in order that hereafter these results may permit one to gather the profit which they are capable of giving, the cultivator and the spinner must give their help and each one their contribution according to his means for the methodical propagation of those varieties which circumstances may impose.

The Ministry of Agriculture and the State Domains which have all the means at their disposal could perhaps focilitate my task so as to obtain a quicker propagation and to preserve the pure strain of my varieties. I think that these administrations could oliminate for the future the difficulties which have prevented them doing this up to now. As far as I am concerned, I will continue to do my duty with the slender means at my disposal. So, during these last years, owing to the reasons of the diminution in the out-turn of the crop, to the degeneration in the varieties of "Ashmoun" in Upper Egypt, and "Sakellarides " in Lower Egypt, and owing to the diseases which affect these regions, I thought it my duty to push on and try and increase as much as possible the production which has declined so perceptibly.

With this object I picked the "Zagora" variety out of my own varieties for Upper Egypt, and this has propagated very rapidly. This variety yields a crop double at times that of the "Ashmoun." It gives an out-turn of 10 per cent more when it is ginned, and is a satisfactory quality.

The advantages which it possesses are the reason for which this variety has soreed itself on to the cultivators of Upper Egypt notwithstanding much opposition from certain powerful quarters, which I still continue to consider inexplicable. All Upper Egypt, with the exception of some small places, is actually cultivated with this variety. The fact that in spite of opposition the propagation of this variety could not be stopped again proves to us that it is the cultivator who chooses the variety which suits him as regards production, its out-turn when "ginned" and its resistance to diseases; and it is the cultivator who at the end of it all selects and produces the quality with which he can provide the spinner.

For Lower Egypt, I propagated my " Pilion " variety, the quality of which is something between "Nubari" and "Sakellarides"; its fibre is strong, and gives spinners a very good out-turn.

This variety has the same advantages as the "Zagora" as regards productiveness, out-turn when ginned, and resistance to diseases. It is more precocious than the other varieties cultivated in Lower Egypt. Its outturn when ginned is from 15 to 20 per cent higher, and on average produces between 40 and 120 per cent more cotton than the "Sakellarides." And because the plant is vigorous the crop has a higher classification. That is to say, it belongs to the classification " good " and even better, and very little of it would be classed inferior to "good."

"Pilion" is actually being cultivated in all the districts of Lower Egypt, and owing to its advantages there is no doubt that next year it will take on as rapidly as the "Zagora" has done in Upper Egypt.

I would call your attention to this eventuality, and $I$ think it is my duty to tell you that it is of great importance that you should seriously study the quality of this variety which will shortly become the largest part of the Egyptian production. You will find that this quality will satisfy the cotton industry for 80 per cent if not more of its requirements and for which it now uses " Sakellarides."

The quality of this variety has already been much. appreciated in some industrial centres, where it has been found that the fibre spins into very good yarn 
without "nep," quite fit on account of its strength and elasticity to be used in the making of tyres.

This is then what is actually being done in Egypt, and where, as I have shown you that where cotton is concerned "necessity is law."

Nevertheless, Egypt could certainly do even better; but as I told you they are doing what they can. As far as I am concerned, pursuing the path which I mapped out for myself, I am about to develop some varieties which besides having the advantages for the cultivator of the productiveness of "Zagora" and "Pilion," are capable at the same time of producing qualities similar or superior to "Sakellarides," which sooner or later will disappear.

The results already achieved authorise me to consider that we have found the key which will allow us to preserve the standard of the Egyptian production, to hope that this production will increase and that the high standard of Egyptian cotton will be maintained.

Mr. T. Fletcher Robinson (Manchester) proposed a vote of thanks to the lecturer and chairman, and said the members of the Institute were glad to have had the advantage of the lecturer's experience in the cotton fields of Egypt.

Mr. I. W. McConnel (Manchester) seconded, and the vote was heartily accorded.

\section{REVIEWS}

A Summer Tour (1919) Through the Textile Distriots of CANADA AND THE UNITEd States. By Aldred F. Barker, M.Sc., Professor of Textile Industries in the University of Leeds. (Jowett and Sowry Ltd., Leeds).

As the author suggests, in the preface to this record of a most interesting tour, he has not been able to avoid a personal tendency to literary vagrancy. Whilst there is a good deal of wandering from the subject which the title of the book indicates, nevertheless the reading does yield a really convincing impression as to some of the experiences which might be expecterl in the course of a tour of the character in question. The photographic illustrations are both numerous and well chosen, and many interesting statements and comparisons are presented in relation to social, political, and industrial conditions. On the whole, there is perhaps a disproportionate amount of matter in reference to affairs in general rather than to the textile industries in particular in the areas toured. Still, the combination of the "literary vagrancy" with the more purposeful description of the conditions attaching to the textile industry centres cannot be said to be unsuccessful. The author considers that a Canadian cotton mill is usually much more interesting to visit than a Lancashire cotton mill, as all operations of manufacture are conducted on the same mill premises in the case of Canada. It is said that, on the whole, " the Canadian wool mills come up to the best Yorkshire mills-some few Yorkshire mills are better, many are very much worse." A point is made that, through. out Canada, especially in regard to cotton, although automatic looms are much in evidence, yet they are run very slowly. The conditions in the Canadian hosiery industry are stated to be superior to those obtaining in the other textile sections, surgesting arading according to the lateness or rorliness of developmont. The author deals with the adueational facilities of Canada, the housing problem, and many other matters, and draws the inference, from the fact that there is an almost unlimited water supply to hand all over the country, that manufacturing prospects are "obviously rosy."

For the reason that many descriptions of conditions in the U.S.A. textile arens have been published of late. reference is not here made to this section of the work, On the whole, the book is readable, and, at any rate, it represents an obviously sincere effort to produce an entertaining and perhaps useful record of a modern tour to the West.

Fiax ANd its Products. By H. R. Carter. (Bale and Danielsson Ltd., London. 10s. 6d. net).

The title of this work appears to have been suggested by that of a well-known book entitled "Flax and its Products in Ireland." The first 70 pages deal with the cultivation of the flax plants, the methods of removing the fibrous layers, and the subsequent operations of breaking and scutching, and in this respect the matter. is very similar to other published literature on the same subject. In this section, several illustrations appear which are similar to those which are published as a picture post-card series by the Courtrai firm, Masquelier Soeurs, Succ. de Beyaert-Filleul. This series of views is exceedingly interesting, and readers are advised to see them if possible.

Lithographic views and line drawings of breaking and scutching machines are given, but the line drawings could, with advantage, have been more earefully made.

The whole of the operations involved in the manu. facture (spinning) of yarn and thread is disposed of in 18 pages; plain and figured linen weaving occupies 6 pages; and the description of finishing and printing occupies 7 pages. Then follows 5 pages containing brief remarks about linseed oil, linseed cake manufac. ture, and other products.

The above contribution on 107 pages constitutes really the subject matter of the title, and one could hardly expect the subject to be treated exhanstively in such $\mathrm{n}$ small space.

By far the larger part of the hook, termed the appendix, pages 108 to 308 , is simply the introduction of a mass of letters, extracts and the like-some of it duplicated-culled from various newspapers, guides, and reports. While we deprecate the padding of text books by such literature as the correspondence between farmers and others as to what price should be paid for the growing of flax, we must admit that the republica. tion of those sections headed " Research in the Linen Tracle" and "Scientific Research and the Linen Trade" are bound to have a beneficial effect upon such an important industry. Indeed, the latter series of articles, occupying nearly 40 pages of the appendix and which were written by Mr. John C. Curtiss for the Belfast press, should be printed by the Linen Research Association as a separate pamphlet and sent broadcast to everyone interested in the preparation of the flax fibre and its subsequent treatment. - T. W. 